\title{
EXPLORE
}

\section{Aplikasi Informasi Gedung Serbaguna di Wilayah Kota Depok sebagai Media Pengiklanan dan Fitur Markah untuk Penunjang Keputusan Berbasis Android}

\author{
Hendra Cipta, Fiska Avelia, Yosa Malina Pratiwi, Nur Ismawati \\ Fakultas Ilmu Komputer \\ Universitas Mercu Buana Universitas Lampung \\ Jakarta, Indonesia \\ 141816320007@student.mercubuana.ac.id,41816320008@student.mercubuana.ac.id, \\ 41816320005@student.mercubuana.ac.id,nurismawati@mercubuana.ac.id
}

\begin{abstract}
Advertising media can be used for promotion of buildings for various purposes and needs such as weddings, meeting, graduation ceremony, seminars, family gathering, etc. promotion buildings and searching for building data sources through social networks or online sites is not yet fully effective because it takes a lot of time and the data obtained is not necessarily complete and accurate. This study aims to answer the needs of building managers and building seekers by an application. Methodology and application development using SDLC (Software Development Life Cycle) with Waterfall development model. The results of this application are expected to make it easier and help people to get reliable and accurate information sources, as a medium for advertising and decision support.
\end{abstract}

Keywords: Android, Aplikasi, gedung, Informasi, Watertfall

\begin{abstract}
Abstrak-Media pengiklanan dapat digunakan untuk kebutuhan promosi gedung serbaguna untuk berbagai keperluan dan kebutuhan seperti acara pernikahan, pertemuan kantor, acara wisuda, acara seminar, acara keluarga, dan lain sebagainya. Mempromosikan gedung dan mencari sumber data gedung melalui jejaring sosial ataupun situs daring belum sepenuhnya efektif karena banyak menghabiskan waktu dan data yang didapatkan belum tentu lengkap dan akurat. Penelitian ini bertujuan untuk menjawab kebutuhan dari pengelola gedung dan pencari gedung dengan membangun sebuah aplikasi. Metodologi dan Pengembangan aplikasi ini menggunakan SDLC (Software Development Life Cycle) dengan model pengembangan Waterfall. Hasil dari aplikasi ini diharapkan mempermudah dan membantu masyarakat untuk mendapatkan sumber informasi terpercaya dan akurat, sebagai media pengiklanan dan penunjang keputusan.
\end{abstract}

Kata Kunci: Android, Application, Building, Information, Waterfall

\section{Pendahuluan}

Pembangunan dan perkembangn gedung di wilayah kota Depok sangat maju dengan cepat dengan semakin berkembangnya jaman dan teknologi. Biasanya masyarakat menggunakan gedung untuk berbagai keperluan dan kebutuhannya. Seperti halnya acara pernikahan, pertemuan kantor, acara wisuda, acara seminar, acara keluarga, dan lain sebagainya.

Era digital saat ini ada begitu banyak macam media iklan untuk mempromosikan gedung. Pengelola gedung dapat mempromosikan gedung miliknya melalui jejaring sosial maupun situs daring. Namun apakah hanya dengan cara tersebut efektif untuk menarik banyak penyewa atau pelanggan?
Bagaimana dengan masyarakat atau calon penyewa gedung mendapatkan sumber data gedung yang lengkap untuk kebutuhannya? Proses pencarian gedung atau tempat yang sesuai dengan kebutuhan sangatlah tidak mudah dan banyak menghabiskan waktu. Jika mencari dari sumber data situs daring cukup memakan waktu dan sulit untuk membandingkan dengan beberapa tempat sekaligus. Dari menghabiskan pencarian di situs daring apakah sumber data informasi gedung yang didapatkan merupakan sumber data terbaru? Apakah data tersebut akurat? Apakah hasilnya bisa menjadi bahan penunjang keputusan?

Data yang paling krusial adalah nomor telepon si pemilik gedung untuk mempermudah calon penyewa 
untuk booking gedung atau sekedar bertanya informasi lengkap tentang gedung tersebut. Sayangnya terkadang nomor telepon tersebut terhubung dengan perantaraperantara. Belum lagi calon penyewa harus mengujungi tempat secara real untuk memastikan apakah calon gedung tersebut sudah sesuai dengan kebutuhan yang diinginkan. Mulai dari kecocokan harga, tempat, lokasi, fasilitas, hasil ulasan penyewa sebelumnya dan detai lainnya. Dari hal ini menyebabkan calon penyewa gedung membutuhkan banyak waktu untuk mencocokkan segala hal agar acara yang diselenggarakan berjalan dengan baik.

Lalu berdasarkan latar belakang diatas, paper ini akan menjelaskan bagaimana sebuah aplikasi android bisa menjawab persoalan dan kebutuhan dari kedua pihak, penyewa gedung maupun pemilik gedung untuk membawa hasil data yang tepat bagi penunjang keputusan.

\section{Dasar Teori}

\section{A. Metode Pengembangan Sistem}

Metode pengembangan sistem yang digunakan adalah metode Software Development Life Cycle (SDLC) dengan model pengembangan Waterfall. Untuk menghasilkan sistem yang berkualitas baik perlu dikerjakan secara berurutan dan sistematis, lebih dapat dipahami oleh pengguna maupun developer. Berikut tahapan umum model pengembangan Waterfall, yaitu (5):

\section{Analis Kebutuhan}

Membuat studi kelayakan untuk sistem aplikasi yang akan dibuat, mempelajari data sample dari distribusi kuesioner, agar ditarik kesimpulan apakah sistem aplikasi yang akan dibangun dapat menjadi penunjang keputusan bagi penggunanya berdasarkan kelayakan secara teknis, kelayakan operasi, dan kelayakan kegunaannya seperti yang bisa dilihat pada gambar 1, 2, 3, 4 dan 5 .

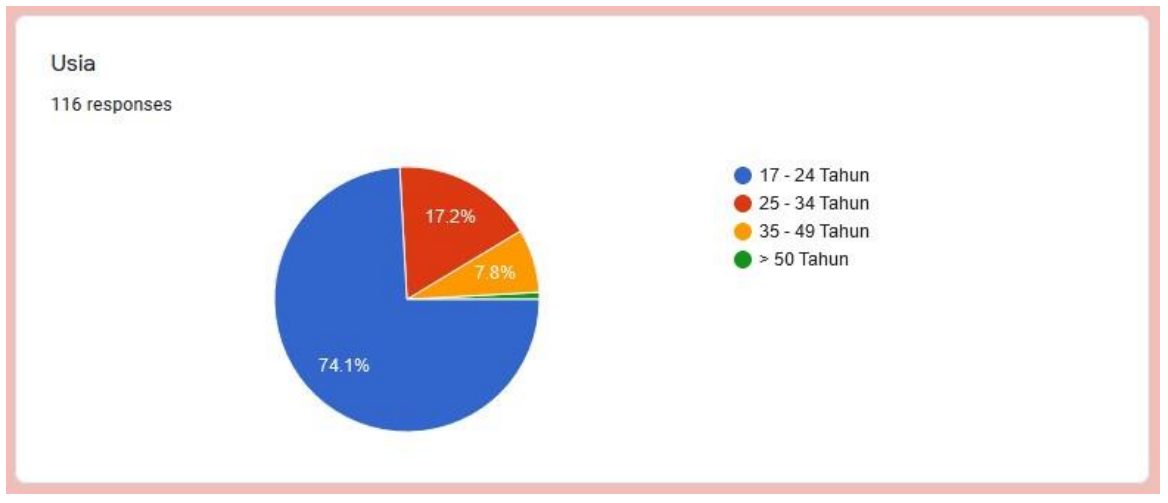

Gambar 1. Data Usia pengisi kuesioner

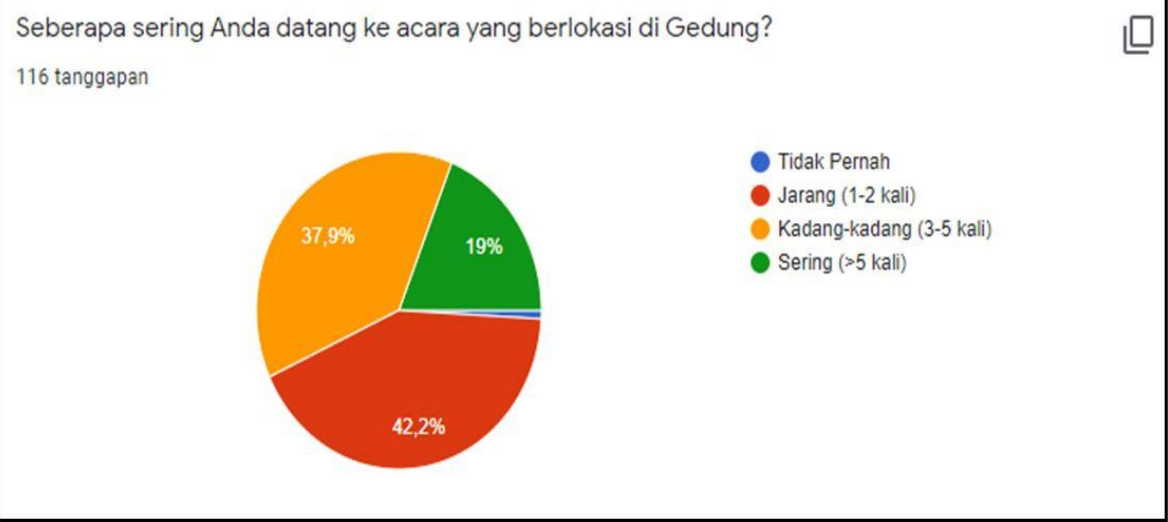

Gambar 2. Data Seberapa Sering Mengunjungi Gedung 
Apakah acara yang Anda kunjungi saat itu?

116 responses

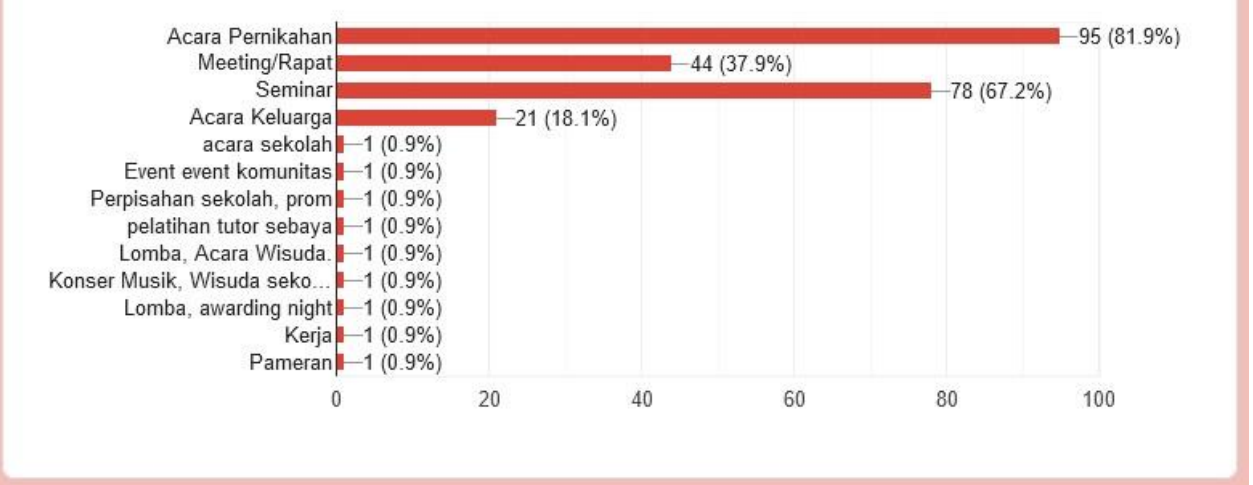

Gambar 3. Jenis Acara yang dikunjungi

Masalah apa yang biasanya Anda hadapi dalam mencari informasi tentang penyewaan Gedung?

117 responses

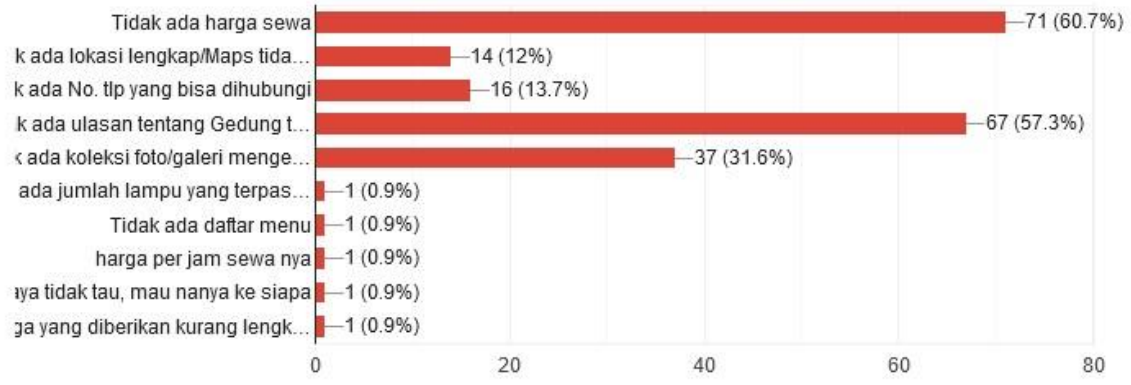

Gambar 4. Masalah saat mencari informasi gedung

Jika ada Aplikasi Mobile Android untuk memenuhi kebutuhan atas Informasi perihal tersebut, apakah akan membantu menjawab kebutuhan Anda?

117 responses

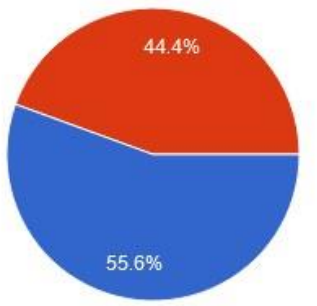

Sangat membant

Cukup membantu

Tidak membantu

Gambar 5. Survey Aplikasi Informasi Gedung

\section{Desain Sistem}

Menganalisa struktur dan alur sistem yang akan dibangun meliputi rancangan anlisa proses yang sedang berjalan, analisa kebutuhan sistem, use case diagram, use case description, activity diagram, dan class diagram.

\section{Coding}

Merancang sistem antarmuka pengguna yang menarik dengan acuan data yang diperoleh dari kuesioner berdasarkan jenis kelamin dan usia agar mendapatkan tampilan antarmuka aplikasi bisa diterima oleh pengguna. Setelah itu dilakukan tahap pembuatan aplikasi ke dalam kode-kode dengan menggunakan bahasa pemrograman 
yang ditentukan berdasarkan acuan semua objek antarmuka pengguna.

\section{Testing (Pengujian Program)}

Aplikasi yang dibangun langsung diuji baik secara unit dan fungsi-fungsi sebelumnya untuk meminimalisir kesalahan sistem pada situasi sebenarnya.

\section{Maintenance (Pemeliharaan Program)}

Melakukan pemeliharaan sistem aplikasi, mengoperasikan di lingkungannya dan penyesuaian atau perubahan karena adaptasi dengan situasi sebenarnya.

\section{B. Penelitian Terkait}

Penelitian terkait perangkat lunak yang memberikan informasi gedung serbaguna telah dilakukan oleh beberapa peneliti dari berbagai perspektif, antara lain [4] $-[9]$.

Penelitian oleh [4], menangani proses reservasi, transaksi dan laporan pada perum Bulog. Aplikasi digunakan oleh dua pengguna, yaitu pengelola dan pelanggan dengan menggunakan metode waterfall.

Penelitian oleh [5], mengelola proses reservasi, transaksi dan melaporkan transaksi reservasi online untuk membantu pelanggan dan pemasaran menjadi lebih efektif dan efisien.
Penelitian oleh [6] mengenai website sebagai media akses dan transaksi. Salah satu kelebihan dari sistem yang dibuat adalah mempermudah pengguna/pemesanan untuk melakukan pemesanan gedung Alpha.

Penelitian oleh [7] memberikan kemudahan bagi penyewa untuk mendapatkan informasi jadwal gedung serbaguna yang ada dan melihat harga, fasilitas, paket, item yang ditawarkan.

Penelitian oleh [8] tentang informasi lokasi gedung dan komponen-komponen seperti harga sewa, jarak, kapasitas dan fasilitas di dalamnya akan disajikan melalui sebuah sistem informasi berbasis web. Memudahkan masyarakat untuk mencari informasi dan memilih gedung sesuai dengan kriteria.

Penelitian oleh [9] menawarkan kemudahan bagi para konsumen untuk mendapatkan informasi mengenai penyewaan gedung HKBP Bandung Barat.

Penelitian diatas merupakan penelitian terkait yang digunakan untuk menyelesaikan penelitian ini. Berdasarkan penelitian diatas belum ada yang fokus membahas mengenai fitur-fitur yang spesifik seperti fitur "tambahkan gedung" sebagai media pengiklanan, dan fitur "markah" untuk penunjang keputusan.

\section{Metodologi Penelitian}

Penelitian terbagi menjadi beberapa tahapan seperti gambar 6 dibawah ini:

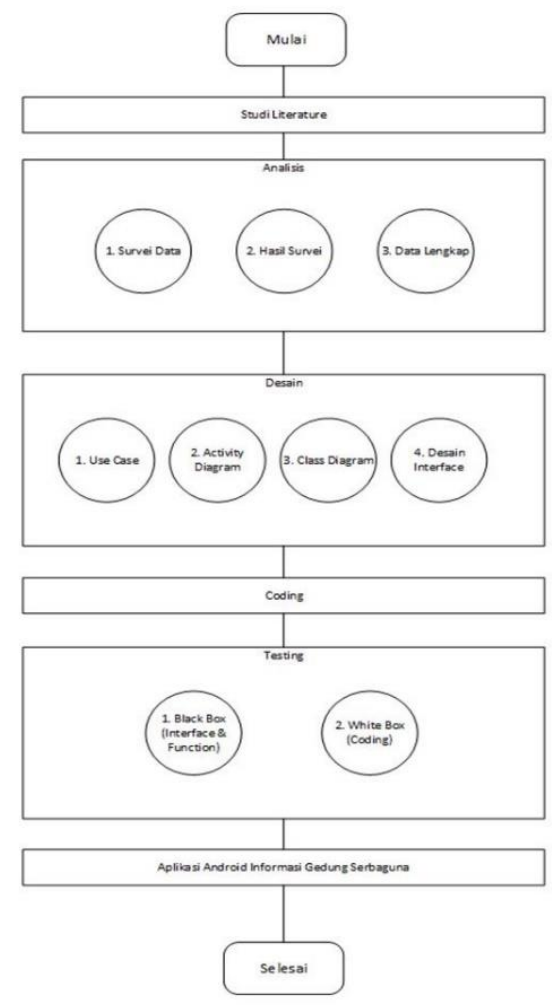

Gambar 6. Tahapan Penelitian

Berikut penjelasan setiap tahapan penelitian:

1. Studi literatur dilakukan untuk mengumpulkan informasi yang relevan terkait topik dan masalah yang sedang diteliti.
2. Dalam tahap analisis metode mengumpulkan data yang kami gunakan adalah menyebar kuesioner berupa pertanyaan ke responden. Hasil data yang 
terkumpul diharapkan bisa menunjang berbagai kebutuhan masyarakat.

3. Dari data tersebut kami membuat desain rancangan sistem seperti use case, activity diagram dan class diagram. Selanjutnya divisualisasikan sebagai rancangan antaramuka pengguna.

4. Programmer membangun aplikasi sesuai rancangan sistem dan desain antarmuka.

5. Sebelum aplikasi siap digunakan, terlebih dahulu dilakukan whitebox testing maupun blackbox testing untuk menghindari dan meminimalisir kesalahan sistem.

\section{Hasil dan Pembahasan}

Dalam pengembangan aplikasi informasi gedung serbaguna digambarkan pada bentuk Unified Modelling Language (UML) dan User Interface (UI) desain.

Use Case Diagram digambarkan aktivitas yang dilakukan antara sistem dan pengguna aplikasi seperti pengunjung mendaftarkan akun baru, pengunjung masuk aplikasi dengan login, pengunjung dapat melihat semua informasi gedung, pengunjung yang sudah login dapat membuat ulasan gedung, pengunjung juga dapat mendaftarkan gedung baru bagi pemilik gedung seperti yang bisa di lihat pada gambar 7 .

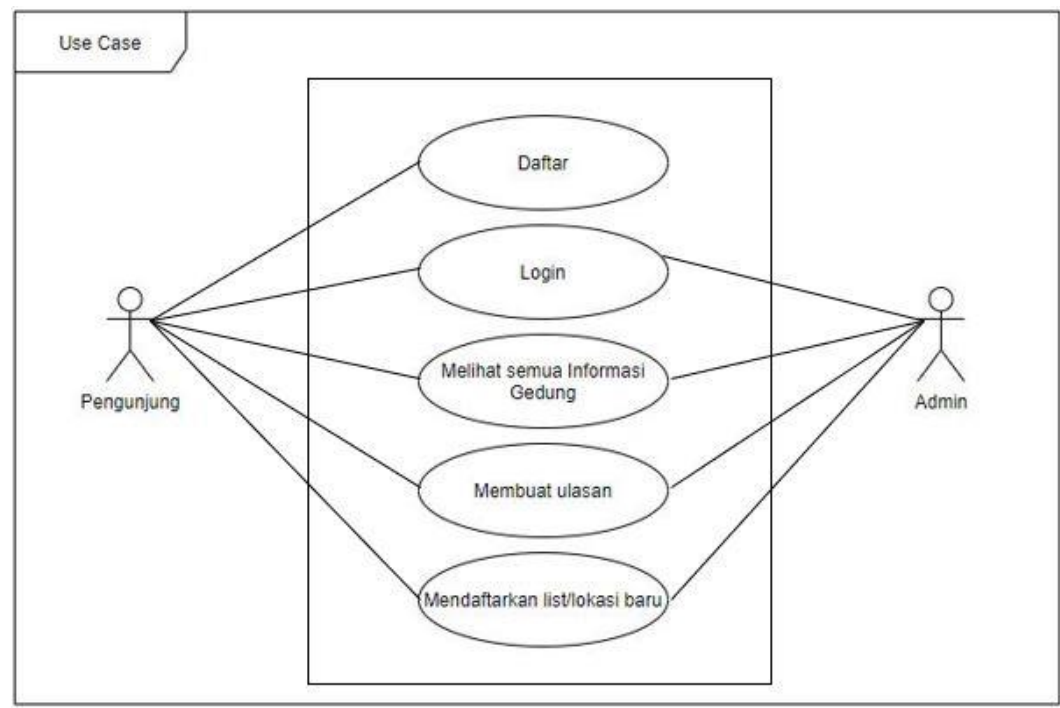

Gambar 7. Use Case Diagram Aplikasi

Pada tampilan beranda terdapat tampilan list gedung, terdapat menu filter berdasarkan harga tertinggi hingga terendah, filter berdasarkan wilayah kecamatan kota Depok. Ada tiga kategori menu seperti Aula, Co-Working Space dan Villa. Pengunjung bisa melihat rekomendasi gedung paling baru dan rekomendasi gedung yang peringkatnya paling memuaskan. Dan juga terdapat fitur Ads yaitu dimana pemilik gedung bisa mengiklankan gedung miliknya sendiri sehingga meningkatkan promosi gedungnya, bisa dilihat pada gambar 8 .

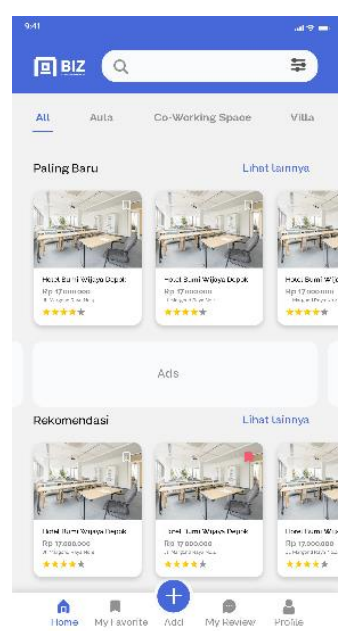

Gambar 8. Tampilan Beranda

Setelah pengguna melakukan login maka akan dapat melihat fitur harga dan telepon pemilik gedung, gambar gedung terbaru, detail deskripsi, fasilitas, dan review pengunjung lainnya, bisa dilihat pada gambar 9 . 


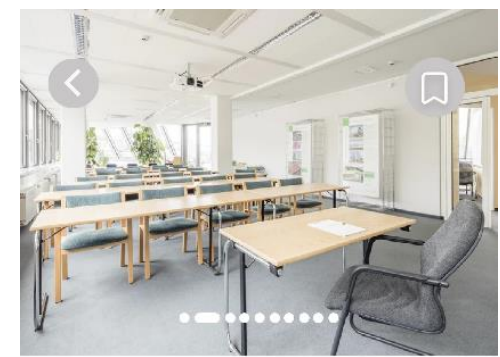

Hotel Bumi Wijaya Depok

Rp $17,000,000$

Jl. Margond Raya No.4

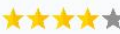

Deskripsi

Lorem Ipsum Dolor Sit Amet, Consetetur Sadipscing Elitr.

Sed Diam Nonumy Eirmod Tempor Invidunt Ut Labore Et

Dolore Magna Aliquyam Erat, Sed Diam Voluptua, At Vero

Eos Et Accusam Et Justo Duo Dolores Et Ea Rebum. Stet

Clita Kasd Gubergren, No Sea Takimata Sanctus Est Lorem

Ipsum Dolor Sit Amet. Lorem Ipsum Dolor Sit Amot .

Lihat lebih banyak

Fasilitas

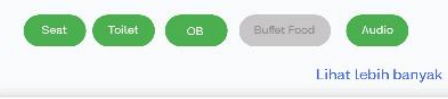

Herga Mutai Dari

Rp 5.000 .000

Gambar 9. Tampilan Detail Gedung

Pengunjung yang sudah login dapat menambahkan terdapat pilih jenis gedung, isi lengkap deskripsi, harga, gedung baru, lalu mengisi detailnya sebagaimana alamat, bisa dilihat pada gambar 10 .

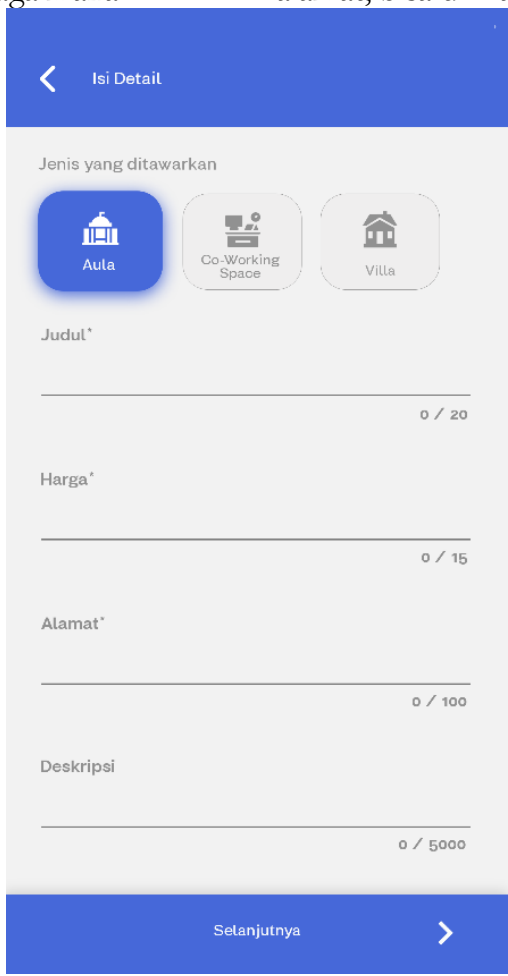

Gambar 10. Tampilan Tambah Gedung Baru

Pengguna dapat memberikan ulasan, penilaian dengan keamanan, kenyamanan, fasilitas, akses, pelayanan, dan bintang sesuai indikatornya dari segi kebersihan, harga, bisa dilihat pada gambar 11 . 


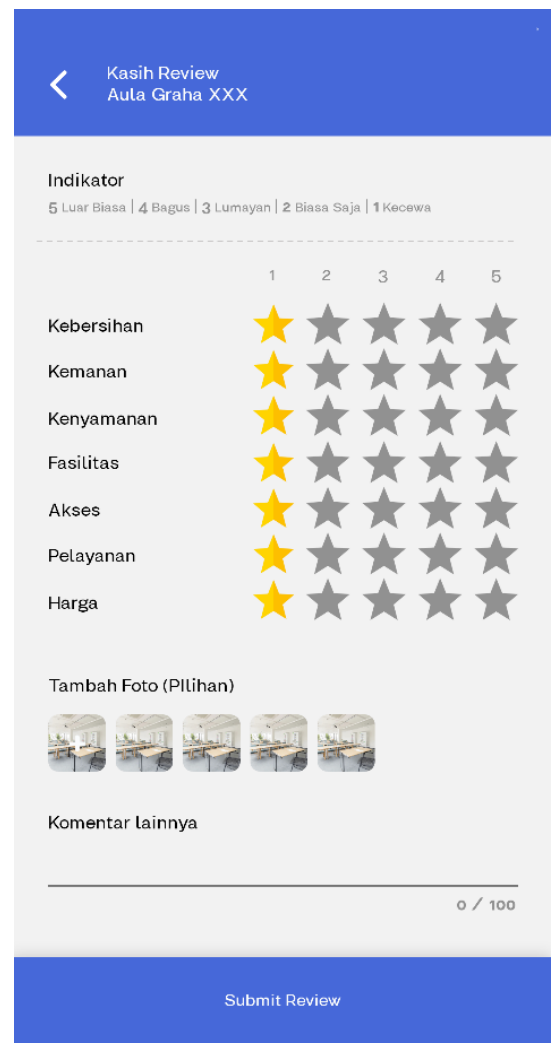

Gambar 11. Tampilan Ulasan

Fitur markah untuk menyimpan iklan gedung yang pengguna minati. Bertujuan agar menghemat waktu pencarian dan sebagai penunjang keputusan, bisa dilihat pada gambar 12 .

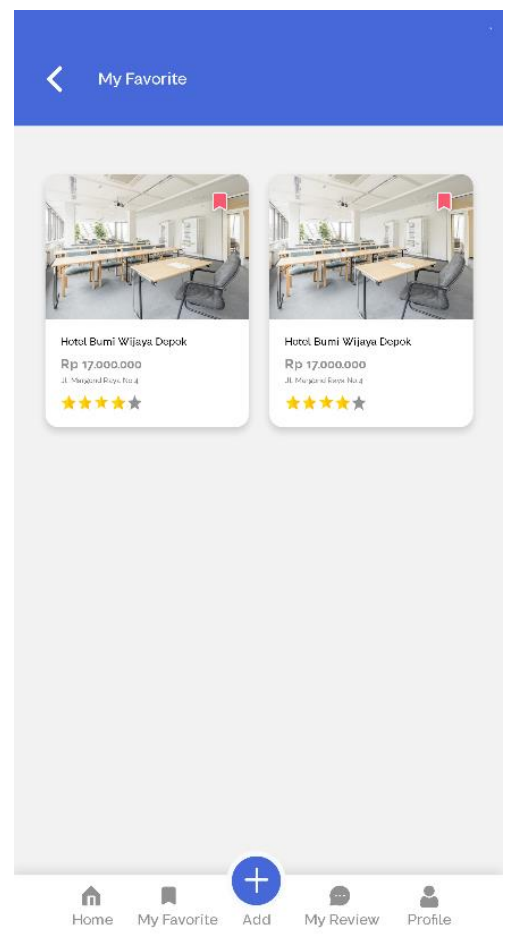

Gambar 12. Tampilan Menu Markah

Salah satu fitur yang dapat langsung terhubung pada pemilik gedung tanpa adanya perantara yaitu fitur direct call, bisa dilihat pada gambar 13 . 


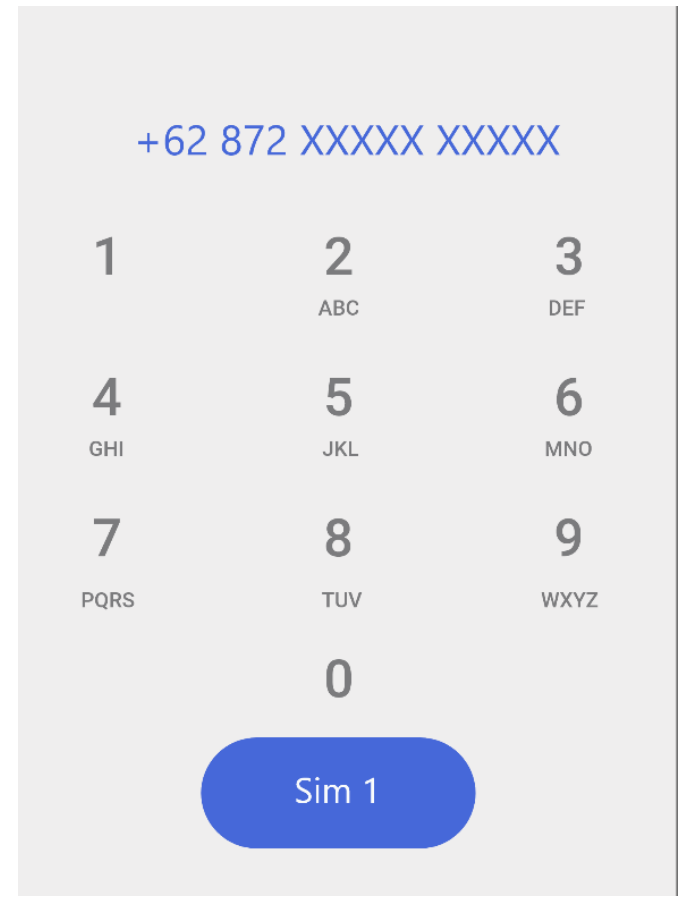

Gambar 13. Tampilan Direct Call

Tampilan Perancangan Keluaran (report) dari hasil mudah dimengerti, dan hasil Report ini juga dapat review, penilaian, dan penambahan iklan. Di sini dapat dijadikan sebagai bahan pertimbangan selanjutnya, bisa dilihat semua laporan dalam bentuk grafik agar lebih dilihat pada gambar 14.

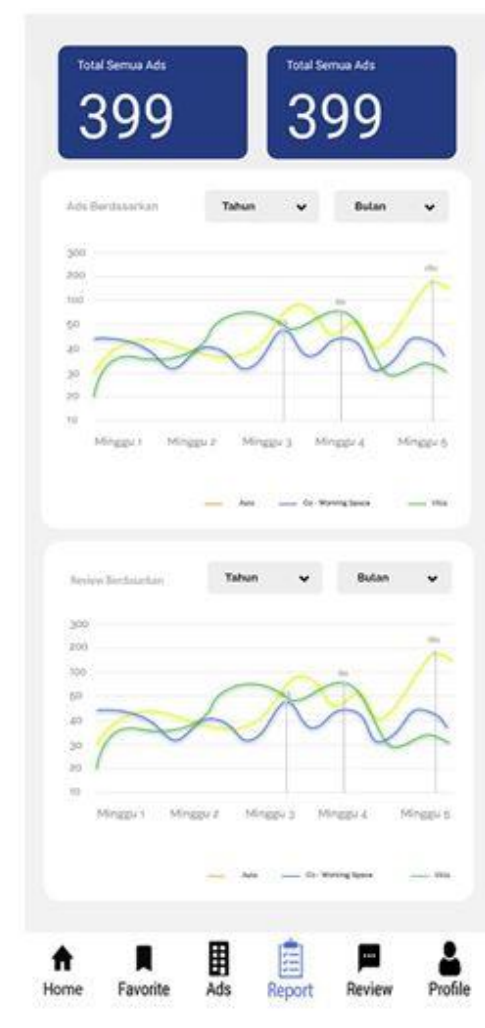

Gambar 14. Tampilan Output Grafik 
Pengguna dapat menyaring iklan berdasarkan harga, mulai dari yang terendah sampai dengan tertinggi ataupun sebaliknya. Ketika pengguna sudah melakukan input untuk menyaring iklan, sistem akan menampilkan hasil penyaringan tersebut. Dapat dilihat pada gambar 15.

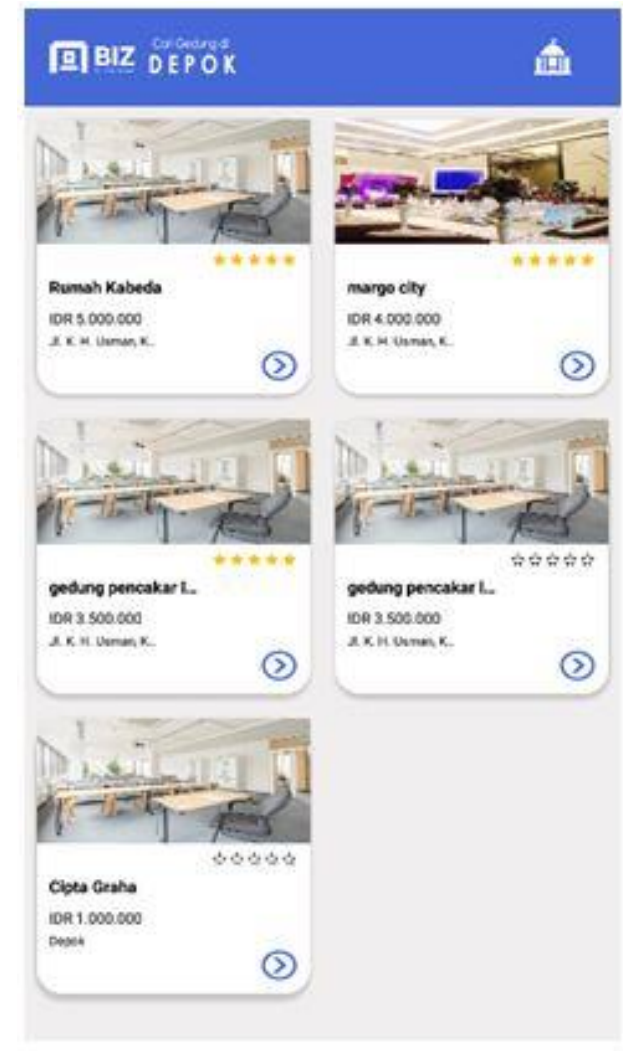

Gambar 15. Tampilan Output Filter Harga

Begitu juga dengan filter wilayah, sistem akan menampilkan hasil penyaringan setelah pengguna melakukan input. Perhatikan Gambar 16.

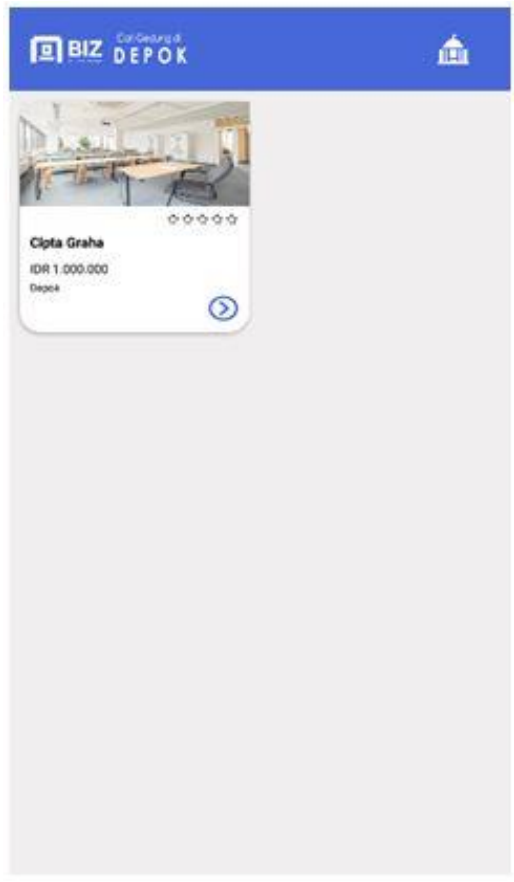

Gambar 16. Tampilan Output Filter Wilayah 
Sistem akan menolak beberapa fitur kemudian menampilkan output diperlihatkan pada Gambar 17, 18, dan 19 jika pengguna belum melakukan login.

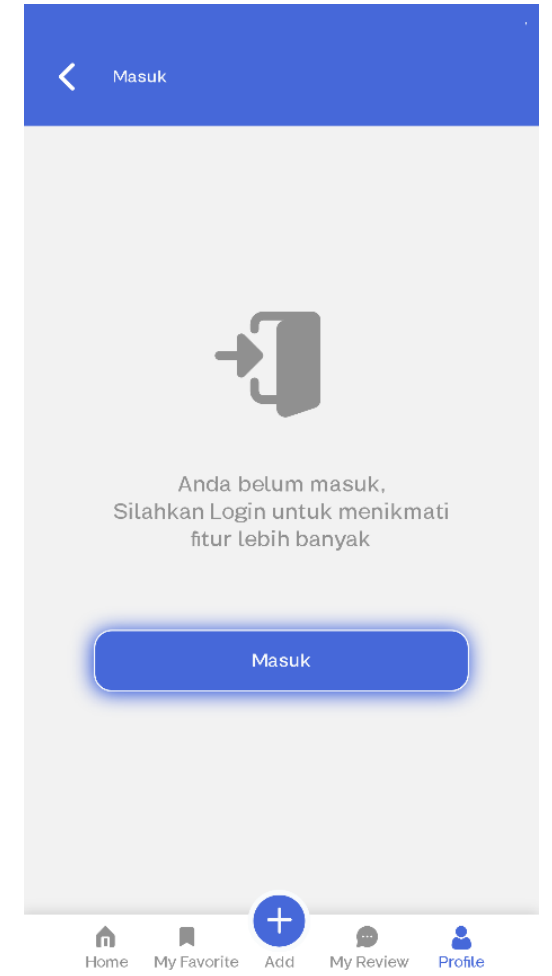

Gambar17. Tampilan Output Login Gagal

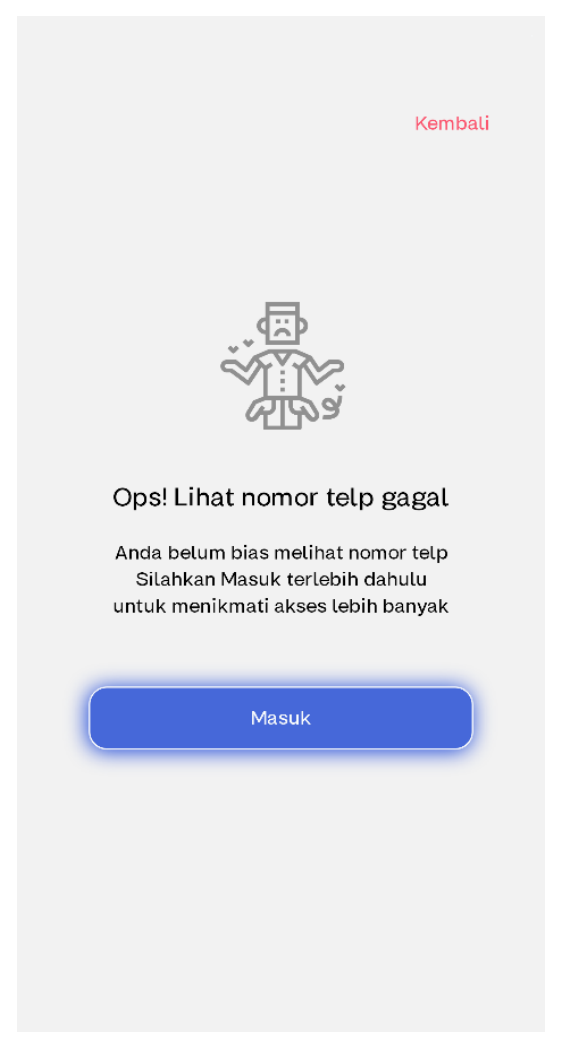

Gambar 18. Tampilan Output Telepon Gagal 


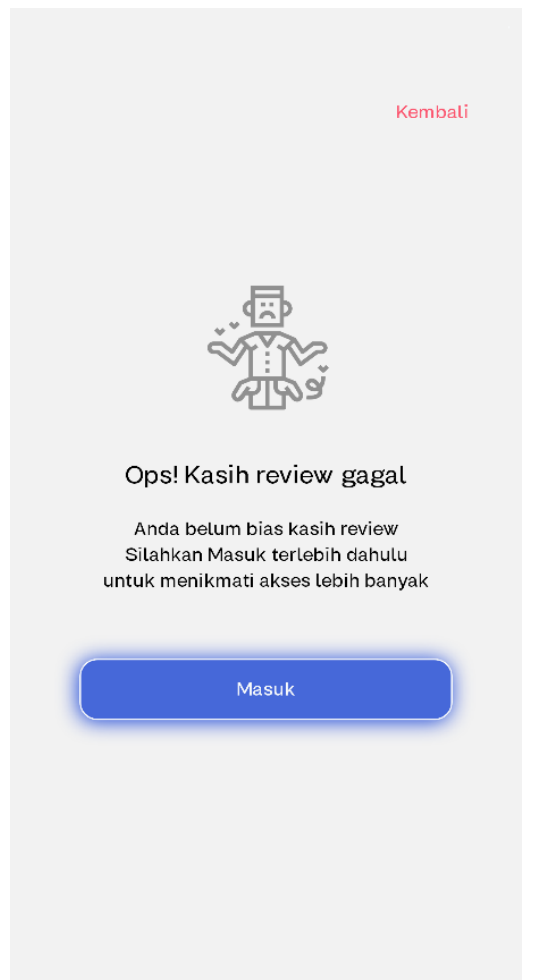

Gambar 19. Tampilan Output Kasih Review Gagal

\section{Kesimpulan dan Saran}

Berdasarkan hasil kuesioner dan analisa, maka dapat diambil kesimpulan bahwa adanya Aplikasi Informasi Gedung Serbaguna Di Wilayah Kota Depok Bebasis Android dapat membantu masyarakat dalam memilih dan menentukan sebuah Gedung atau tempat yang dapat digunakan untuk keperluan pribadi maupun koorporat, karena dalam aplikasi ini memiliki fitur yang bisa dijadikan sebagai tolak ukur dalam pemilihan seperti range harga, fasilitas, review pengunjung, mendapat kontak langsung kepada pemilik gedung tanpa perantara, fitur markah untuk penunjang keputusan, dan pengguna dapat menambahkan gedung baru sebagai pemilik gedung untuk meningkatkan minat pengguna lebih banyak.

Dengan dibuatnya sebuah Aplikasi Informasi Gedung Serbaguna Di Wilayah Kota Depok Bebasis Android ini, diharapkan nantinya dapat membantu masyarakat sebagai media pengiklanan dan penunjang keputusan. Kedepannya bisa menambahkan fitur yang lebih menarik serta sistem yang lebih baik, dan semoga bermanfaat untuk warga sekitar.

\section{Daftar Pustaka}

[1] T. Badriyah et al., "Rancang bangun aplikasi sistem rekomendasi pencarian gedung serbaguna," J. Sist. Inf., vol. 9, no. 1, pp. 1-6, 2018, [Online]. Available: http://ejournal.nusamandiri.ac.id/index.php/techno /article/view/105.

[2] H. Lusti and F. Masya, "Analisa Perancangan Sistem Informasi Pemesanan Pada Wedding Organizer Berbasis Web," CESS (Journal Comput. Eng. Syst.
Sci., vol. 5, no. 1, p. 162, 2020, doi: 10.24114/cess.v5i1.15610.

[3] R. D. Risanty, P. Meilina, and N. A. Hasni, "Perancangan sistem pendukung keputusan prediksi jumlah produksi dan tenaga kerja menggunakan metode," Peranc. Sist. Pendukung Keputusan Prediksi Jumlah Produksi Dan Tenaga Kerja Menggunakan Metod. Fuzzy Sugeno, no. November, pp. 1-6, 2016.

[4] N. Sesnika, D. Andreswari, and R. Efendi, "Aplikasi Sistem Pendukung Keputusan Pemilihan Gedung Serba Guna Di Kota Bengkulu Dengan Menggunakan Metode Smart Berbasis Android," J. Rekursif, vol. 4, no. 1, pp. 30-44, 2016.

[5] F. Ilmu, K. Universitas, B. Darma, A. Hadiansyah, E. Yulianingsih, and T. Ibadi, "Sistem Informasi Reservasi Gedung Menggunakan Metode Rapid Application Development ( Studi Kasus Gedung Graha Tharra Palembang ) Bina Darma Conference on Computer Science 2019," pp. 163-173, 2019.

[6] A. A. Prasetia, "Sistem Informasi Reservasi Gedung Serbaguna di Kota Palembang Berbasis Android," J. Intelekt. Keislaman, Sos. dan Sains, vol. 7, no. 1, pp. 121-128, 2018, doi: 10.19109/intelektualita.v7i1.2344.

[7] M. M. Ghazali, "Sistem Penunjang Keputusan Pemilihan Gedung Serbaguna dengan Menggunakan Metode Topsis (Studi Kasus: Kota Banjarmasin), JIntech, vol. 4, no. 01, pp. 107-114, 2016, [Online]. Available: INTECH/article/view/70.

[8] Fachriza Rajab Muhammad and Paimasrul, "Information Sistem Web-Based Multipurpose 
Building Rental In HKBP Bandung Barat,” pp. 1-7. Bandung : Universitas Komputer Indonesia, 2019.

[9] R. Liwang, N. Hendrawan, and D. Program Studi Teknik Informatika, "Rancang Bangun Aplikasi
Website Sebagai Media Manajemen Pendaftaran Pemesanan Gedung Aula Metro Baubau,' J. Inform., vol. 8, no. 1, pp. 65-73, 2019, [Online]. Available: http://ejournal.unidayan.ac.id/index.php/JIU. 